\title{
Patient Load
}

National Cancer Institute

\section{Source}

National Cancer Institute. Patient Load. NCI Thesaurus. Code C52646.

The number of patients who are evaluated or treated in any given period of time. 